\title{
Retracted Article: Interleukin-1beta and tumor necrosis factor-alpha regulation of CDX2 homeobox gene through nuclear factor kappa B-dependent pathway in the intestinal-type gastric cancer
}

Jiang Li $\cdot$ Renhu Sun • Kaixiong Tao •

Guobin Wang

Received: 8 October 2009/Accepted: 26 October 2009/Published online: 12 November 2009

(C) Humana Press Inc. 2010

This article has been published OnlineFirst, but is withdrawn at the author's request.

J. Li · R. Sun $\cdot$ K. Tao $\cdot$ G. Wang $(\bowtie)$

Department of Laparoscopic Surgery Unit, Union Hospital,

Tongji Medical College, Huazhong University of Science

and Technology, 1277 Jiefang Road, 430022 Wuhan,

People's Republic of China

e-mail: wangguobinunion@163.com 